ARTIGO TEMÁTICO: PÓS-GRADUAÇ̃̃O E SERVIÇO SOCIAL

\title{
As pesquisas científicas do Serviço Social: o papel do $\mathrm{CNPq}$
}

\author{
Daniella Borges Ribeiro
}

Universidade Federal de Ouro Preto (UFOP)

\section{As pesquisas científicas do Serviço Social: o papel do CNPq}

Resumo: Este artigo tem como objetivo delinear um panorama das pesquisas do Serviço Social financiadas pelo CNPq entre os anos de 2011 e 2014. É uma pesquisa de cunho documental, de abordagem quali-quantitativa, elaborada a partir das planilhas enviadas pelo CNPq contendo dados dos projetos de pesquisa submetidos e aprovados por esta agência entre os anos de 2011 e 2014. Constata que das 7.512 propostas submetidas pelas ciências sociais aplicadas, 355 (4,7\%) eram do Serviço Social e das 2.421 propostas aprovadas, $118(4,9 \%)$ eram do Serviço Social. Entre os temas estudados pelo Serviço Social, foi dado destaque às políticas sociais com ênfase no campo da saúde. Discute as implicações da indução estratégica da pesquisa e das parcerias entre o público e o privado para a produção de conhecimentos e a formação profissional na área.

Palavras-chave: Pesquisa. Serviço Social. Universidade. CNPq. Autonomia científica.

\section{Scientific research on Social Work: the role of CNPq}

Abstract: The aim of this paper is to outline an overview of research on Social Work funded by CNPq (National Council for Scientific and Technological Development), between 2011 and 2014. It is a quali-quantitative, documentary research study, compiled from spreadsheets sent by CNPq containing data on research projects submitted to and approved by this agency between 2011 and 2014 . It was found that Social Work accounted for $355(4.7 \%)$ of the 7,512 proposals submitted by applied social sciences and for 118 (4.9\%) of the 2,421 proposals approved. Among the topics studied by Social Work, emphasis was placed on social policies, particularly in the field of health. The paper brings a discussion on the implications of the strategic induction of research and partnerships between the public and private sectors for the production of knowledge and professional training in the field.

Keywords: Research. Social Work. University. CNPq. Scientific autonomy. 


\section{Introdução}

Antes da criação das universidades no Brasil instituições como o Jardim Botânico do Rio de Janeiro $^{1}$, o Observatório Nacional ${ }^{2}$, o Instituto Bacteriológico do Estado de São Paulo ${ }^{3}$ e o Instituto Manguinhos ${ }^{4}$ já eram espaços de desenvolvimento de pesquisas (MACHADO; ALVES, 2005). A realização de pesquisas no país que era incipiente nos séculos XIX e início do XX, ficou mais robusta com o surgimento das universidades $^{5}$, com a criação do Conselho Nacional de Pesquisa $(\mathrm{CNP})^{6}$, da Campanha Nacional de Aperfeiçoamento de Pessoal de Nível Superior $(\mathrm{CAPES})^{7}$ e com a emergência dos programas de pósgraduação stricto sensu (CURY, 2005; RIBEIRO, 2016a). Embora a Lei de Diretrizes e Bases da Educação de 1961 (LDB) ${ }^{8}$ fizesse menção a programas de pós-graduação, entendia-se que as diretrizes colocadas por este documento não eram suficientes para a normatização do ensino neste grau. Assim, apesar da importância do Estatuto das Universidades Brasileiras, do surgimento da CAPES, do CNP e da LDB (de 1961) Cury (2005) destaca o parecer n 977/65 ou "parecer Sucupira" como o regulamento que instituiu oficialmente a pós-graduação no Brasil. Diante do exposto percebe-se o entrelaçamento entre a pesquisa científica e a universidade, pois esta instituição constituiu-se a partir dos anos de 1970, como o principal lócus da produção de conhecimentos. Em uma publicação de 2014, encontramos a informação de que cerca de $90 \%$ das pesquisas científicas realizadas no país eram provenientes da pós-graduação, e, como estes programas localizam-se majoritariamente nas instituições públicas, podemos dizer que a universidade pública é o principal campo de pesquisas do país (BUENO, 2014).

Se por um lado as universidades se constituem como o campo central para as pesquisas, por outro, muitas não possuem recursos próprios para a realização destas investigações. Neste sentido, a maior agência pública financiadora de pesquisas ao nível nacional é o Conselho Nacional de Desenvolvimento Científico e Tecnológico $(\mathrm{CNPq})$. O CNPq atua por meio do incentivo à capacitação de recursos humanos e também no fomento à pesquisa. $\mathrm{O}$ incentivo à capacitação é realizado mediante a concessão de bolsas de estudo no país e no exterior, e o fomento à pesquisa acontece por meio do apoio aos projetos de pesquisa, a editoração e a realização de eventos (BRASIL, 2015a). Desse modo, as pesquisas realizadas pelo Serviço Social (assim como por outras áreas do conhecimento ${ }^{9}$ ) são submetidas aos editais de apoio à pesquisa do CNPq para a obtenção de financiamento (RIBEIRO, 2016a). A ampliação das pesquisas realizadas pelo Serviço Social também se vincula à emergência da pós-graduação da área. O primeiro curso de mestrado em Serviço Social foi criado em 1972, na Pontifícia Universidade Católica do Rio de Janeiro (PUC/RJ), seguido, no mesmo ano, pelo da Pontifícia Universidade Católica de São Paulo (PUC/SP).

\section{... os dados encontrados sobre}

\section{as propostas de pesquisa do}

\section{Serviço Social aceitas pelo}

CNPq entre 2011 e 2014,

$$
\text { seguem a tendência de }
$$

\section{concentração das pesquisas do}

Serviço Social em torno do

tema das políticas sociais.
Em 1981, surgiu o primeiro doutorado em Serviço Social do Brasil (e também da América Latina) na Pontifícia Universidade Católica de São Paulo (PUC/SP) (YAZBEK; SILVA, 2005). Há ainda que se mencionar que o Serviço Social foi reconhecido como área de conhecimento no CNPq em 1984 (BAPTISTA; RODRIGUES, 1992). Existem no Brasil ${ }^{10} 4.237$ programas de pós-graduação stricto sensu. Desses, 34 são da área de Serviço Social ${ }^{11}$, sendo 16 programas com mestrado e $18 \mathrm{com}$ mestrado e doutorado. Em relação ao número de cursos, contabilizam-se 6.347 cursos de pósgraduação stricto sensu no Brasil, sendo 52 de Serviço Social ${ }^{12}$ ( $34^{13}$ cursos de mestrado e 18 de doutorado) (BRASIL, 2016; RIBEIRO, 2016b).

Sendo o Serviço Social uma profissão que incorporou a pesquisa como um elemento importante na formação e no exercício profissional, parece-nos relevante identificar quais são as tendências da produção de conhecimentos neste campo ${ }^{14}$, a partir dos editais de financiamento a pesquisa lançados pelo CNPq entre os anos de 2011 e 2014. Para a realização deste estudo, foram utilizadas as planilhas enviadas pelo CNPq contendo as propostas de pesquisas submetidas a esta agência no período selecionado. Esta listagem foi cruzada com os dados do site do CNPq, onde consta o nome de todos os pesquisadores que alcançaram a aprovação de projetos. De posse das informações, os dados foram sistematizados em planilhas Excel. Trata-se de uma pesquisa documental e de abordagem quali-quantitativa (MINAYO; GOMES, 2011). 


\section{$\mathrm{O}$ apoio à pesquisa pelo $\mathrm{CNPq}$}

Entre 2011 e 2014 o CNPq lançou 135 editais de apoio à pesquisa aos quais foram submetidos 93.367 projetos e aprovados $24.450^{15}$. Das 93.367 propostas de pesquisa enviadas, 7.512 (8\%) eram das ciências sociais aplicadas, sendo aprovados $2.421(9,9 \%)$ projetos de pesquisa desta grande área. Dos 135 editais, $55^{16}$ não receberam nenhuma proposta de pesquisa da grande área das ciências sociais aplicadas. Esse fato pode ser em parte explicado pelo posicionamento do Ministério da Educação (MEC) e do Ministério da Ciência, Tecnologia e Inovação (MCTI) quanto à indução das pesquisas científicas, sendo os editais de apoio ao pesquisador um instrumento importante para a chamada "indução estratégica". Assim, os editais quando divulgados, já indicam qual a área do saber e quais os temas de estudo serão financiados seguindo as diretrizes do atual VI Plano Nacional de Pós-Graduação - PNPG (2011-2020) e do Livro Azul do MCTI que determinam além da indução por áreas, a indução de temas de pesquisa ${ }^{17}$ (BRASIL, 2010; LIVRO..., 2010; RIBEIRO, 2016a; RIBEIRO, 2016b).

Uma pesquisa realizada por Ribeiro (2016a, p. 260) aponta que dos 135 editais de apoio ao pesquisador do CNPq divulgados entre 2011 e 2014, 126 (93,3\%) indicavam previamente o tema a ser pesquisado; $4(3 \%)$ não especificavam o tema, mas eram voltados para algumas grandes áreas do conhecimento e apenas $5(3,7 \%)$ eram abertos a todas as áreas e temas: "essa forte indução, limita as possibilidades de escolha do pesquisador [...] quanto ao quê e para quê pesquisar, o que nos permite afirmar que a autonomia científica da universidade e, consequentemente, dos pesquisadores nela inseridos, está fortemente comprometida". Deste modo, salientamos que as ciências sociais aplicadas não concorreram a todos os editais do CNPq. Em 2011, as ciências sociais aplicadas enviaram 1.205 propostas de pesquisa, em 2012, 1.866 propostas, em 2013, 2.814 e em 2014, 1.627. Desse quantitativo, foram aprovados em 2011, 456 projetos das ciências sociais aplicadas, em 2012, 482 aprovações, em 2013, 752 e em 2014, 731 (Quadro 1). Os editais que mais atenderam à demanda das ciências sociais aplicadas foram o edital universal e o das ciências humanas, sociais e sociais aplicadas. O edital universal recebeu propostas de todas as áreas do conhecimento e o segundo, embora fosse voltado prioritariamente para as ciências humanas e sociais aplicadas, permitiu a aprovação de projetos de outras áreas ${ }^{18}$. Das 7.512 propostas enviadas pelas ciências sociais aplicadas, $355(4,7 \%)$ eram do Serviço Social e das 2.421 propostas aprovadas, 118 (4,9\%) foram submetidas por pesquisadores do Serviço Social.

\section{Quadro 1 - Propostas submetidas e aprovadas pelo CNPq}

\begin{tabular}{|l|c|c|c|c|c|}
\hline \multicolumn{1}{|c|}{ Ano } & $\mathbf{2 0 1 1}$ & $\mathbf{2 0 1 2}$ & $\mathbf{2 0 1 3}$ & $\mathbf{2 0 1 4}$ & Total \\
\hline N. de projetos enviados pelas CSA & 1.205 & 1.866 & 2.814 & 1.627 & 7.512 \\
\hline N. de projetos enviados pelo Serviço Social & 75 & 110 & 108 & 62 & 355 \\
\hline N. de projetos aprovados das CSA & 456 & 482 & 752 & 731 & 2.421 \\
\hline N. de projetos aprovados do Serviço Social & 25 & 30 & 36 & 27 & 118 \\
\hline
\end{tabular}

Fonte: Elaborado pela autora.

No ano de 2011, 25 projetos de pesquisa do Serviço Social foram aprovados. Com o objetivo de identificar as temáticas estudadas, elencamos no quadro abaixo na última coluna (Quadro 2) o assunto principal de cada pesquisa ${ }^{19}$. É importante salientarmos que muitas pesquisas envolviam discussões de uma determinada política social com recortes de gênero ou geracional, mas, para fins de sistematização dos dados optamos por identificar o tema principal. Observa-se que das 25 pesquisas, 11 envolveram o estudo das políticas sociais com destaque para a saúde (4 pesquisas). Em seguida, a temática mais estudada foi trabalho e trabalho do assistente social (6 propostas). 


\section{Quadro 2 - Projetos de pesquisa do Serviço Social aprovados em 2011}

\begin{tabular}{|c|c|c|}
\hline N. Edital/ Título do projeto & $\begin{array}{l}\text { IES de origem/ } \\
\text { sigla }\end{array}$ & Temática \\
\hline 6/ A lógica territorial na gestão das políticas sociais & UEL & Política social \\
\hline $\begin{array}{l}\text { 6/ Assistência social e transferência de renda: interpelações no território da } \\
\text { proteção social }\end{array}$ & UFPB & Assistência Social \\
\hline $\begin{array}{l}\text { 6/ Espaços sócio ocupacionais e tendências do mercado de trabalho do Servi- } \\
\text { ço Social }\end{array}$ & UFAL & Trabalho \\
\hline $\begin{array}{l}\text { 7/ Desafios interdisciplinares nos processos de formação e de trabalho em } \\
\text { saúde urbana }\end{array}$ & UFRGS & Saúde \\
\hline $\begin{array}{l}\text { 7/ Representações Sociais da Infância no Contexto Histórico da Amazônia } \\
\text { Paraense }\end{array}$ & UFPA & Representações sociais \\
\hline $\begin{array}{l}\text { 7/ O impacto dos grandes projetos na agricultura familiar no município de } \\
\text { Anchieta/ES }\end{array}$ & EMESCAM & Agricultura Familiar \\
\hline $\begin{array}{l}\text { 7/Uma radiografia da violência contra a mulher no Distrito Federal: a porta de } \\
\text { entrada do Instituto Médico Legal }\end{array}$ & $\mathrm{UnB}$ & Violência \\
\hline $\begin{array}{l}\text { 7/ Expectativas de alunos concluintes do } 3^{\circ} \text { ano do Ensino Médio e o novo } \\
\text { campus da Universidade Federal do Recôncavo da Bahia }\end{array}$ & UFRB & Educação \\
\hline 7/ Suicídio e Trabalho no Rio Grande do Sul & UFRGS & Violência \\
\hline $\begin{array}{l}\text { 7/ Palavras e olhares da serrinha: memória socioambiental da Lagoa da } \\
\text { Itaperaoba }\end{array}$ & UECE & Meio ambiente \\
\hline $\begin{array}{l}\text { 14/ Acesso aos serviços de saúde de referência para HIV/Aids no Brasil, } \\
\text { África do Sul e Moçambique }\end{array}$ & UFPE & Saúde \\
\hline 14/ Gestão urbana e planos diretores pós Estatuto da Cidade & UFPI & Questão urbana \\
\hline $\begin{array}{l}\text { 14/ O aconselhamento genético para anemia falciforme e cuidados éticos na } \\
\text { Triagem Neonatal: um estudo qualitativo em Brasília }\end{array}$ & UnB & Saúde \\
\hline 14/ O Serviço Social e o direito à educação básica no município de Franca/SP & UNESP & Educação \\
\hline 14/ O trabalho do assistente Social no SUAS & UNITAU & $\begin{array}{l}\text { Trabalho do assistente } \\
\text { social }\end{array}$ \\
\hline $\begin{array}{l}\text { 14/ Trabalho, política social e serviço social: expansão e precarização do } \\
\text { trabalho do assistente social }\end{array}$ & UEPB & $\begin{array}{l}\text { Trabalho do assistente } \\
\text { social }\end{array}$ \\
\hline 14/A fragilidade do idoso e o Sistema de Atenção Básica de Assistência Social & UFSCAR & Assistência Social \\
\hline $\begin{array}{l}\text { 14/ Representações sociais na profissão e atuação de profissionais e gestores } \\
\text { assistentes sociais }\end{array}$ & UCB & Representações sociais \\
\hline $\begin{array}{l}\text { 14/ Expressões da Violência Sexual contra Crianças e Adolescentes no Aten- } \\
\text { dimento da Proteção Social Especial de Média Complexidade }\end{array}$ & UNIOESTE & Violência \\
\hline $\begin{array}{l}\text { 14/ Arranjos Produtivos Locais e Desenvolvimento capitalista periférico: } \\
\text { uma experiência no Nordeste brasileiro }\end{array}$ & UFPE & Trabalho \\
\hline $\begin{array}{l}\text { 14/ Na quilha da canoa, pescadoras e pescadoras: trabalho, reconhecimento e } \\
\text { Seguro Defeso }\end{array}$ & UFAM & Trabalho \\
\hline $\begin{array}{l}\text { 14/ Crise do Capitalismo e Transformações da Seguridade Social na América } \\
\text { Latina e Europa }\end{array}$ & $\mathrm{UnB}$ & Seguridade Social \\
\hline $\begin{array}{l}\text { 14/ A efetivação do direito à saúde e a proteção social na atenção básica: } \\
\text { desafios para a área de saúde do trabalhador }\end{array}$ & UFRGS & Saúde \\
\hline $\begin{array}{l}\text { 14/ Trabalho e Relações de Gênero: análise da Feminização das Profissões e } \\
\text { Ocupações }\end{array}$ & UnB & Trabalho \\
\hline $\begin{array}{l}\text { 14/ Programas de transferência de renda condicionada na América Latina: } \\
\text { estudo comparado }\end{array}$ & UFMA & Assistência Social \\
\hline
\end{tabular}

Fonte: Elaborado pela autora. 
O Quadro 3 traz a lista de todas as pesquisas do Serviço Social aprovadas pelo CNPq em 2012. Das 30 propostas aprovadas, as temáticas com maior aprovação foram as políticas sociais com ênfase na saúde (4 pesquisas) e 5 sobre a temática: trabalho e trabalho do assistente social.

\section{Quadro 3 - Projetos de pesquisa do Serviço Social aprovados em 2012}

\begin{tabular}{|c|c|c|}
\hline N. Edital/ Título do projeto & $\begin{array}{c}\text { IES de } \\
\text { origem/sigla }\end{array}$ & Temática \\
\hline $\begin{array}{l}\text { 11/ O Programa Minha Casa Minha Vida (PMCMV) nos municípios de Teresina-PI e } \\
\text { Timon-MA }\end{array}$ & UFPI & Habitação \\
\hline $\begin{array}{l}\text { 11/ Avaliação do Trabalho Social e dos Impactos na Vida das Famílias no PMCMV: Muni- } \\
\text { cípio de Osasco/SP }\end{array}$ & PUC/SP & Habitação \\
\hline $\begin{array}{l}\text { 11/ Questão socioambiental e relações sociais de gênero: Avaliação e Monitoramento dos } \\
\text { Impactos Socioambientais }\end{array}$ & UFPE & Meio ambiente \\
\hline 14/Inclusão social e econômica de catadores de materiais recicláveis & UCSAL & Trabalho \\
\hline 14/Estágio curricular obrigatório de serviço social: avanços e impasses & UFS & Formação \\
\hline $\begin{array}{l}\text { 14/ Proposta de apoio técnico de nível superior em apoio a projetos de pesquisa do grupo de } \\
\text { avaliação e estudo programa básico de serviço social }\end{array}$ & UFMA & Formação \\
\hline $\begin{array}{l}\text { 14/Conselhos de Políticas Urbanas e Movimentos Sociais: a ação dos sujeitos da participa- } \\
\text { ção e do controle social }\end{array}$ & UFPA & $\begin{array}{l}\text { Participação e controle } \\
\text { social }\end{array}$ \\
\hline 14/Violência contra a mulher rural e a rede de proteção social no estado do Rio Grande do Sul & PUCRS & Violência de gênero \\
\hline $\begin{array}{l}\text { 14/ Da casa abrigo a casa bazar Novas e velhas formas e funções dos espaços de moradia num } \\
\text { bairro popular }\end{array}$ & UFRJ & Habitação \\
\hline $\begin{array}{l}\text { 14/ Modelagem institucional internacional da política pública de combate à pobreza no } \\
\text { Brasil }\end{array}$ & $\mathrm{PUC} / \mathrm{PR}$ & Pobreza \\
\hline $\begin{array}{l}\text { 14/ Inflexões dos conceitos sociais-liberalistas sobre o marco legal da política de assistência } \\
\text { social }\end{array}$ & UEPB & Assistência Social \\
\hline $\begin{array}{l}\text { 14/ A judicialização da política e da questão social no Brasil: um estudo sobre a atuação dos } \\
\text { juízes e dos assistentes sociais }\end{array}$ & UERJ & Trabalho \\
\hline 14/ Gastos extra-hospitalares em saúde mental & UFES & Saúde \\
\hline $\begin{array}{l}\text { 14/ Uma questão e duas temporalidades: Direito à saúde na fronteira MERCOSUL - 2003- } \\
2013\end{array}$ & UFSC & Saúde \\
\hline $\begin{array}{l}\text { 18/ Avaliação dos impactos ideológicos e políticos dos empreendimentos solidários em } \\
\text { Pernambuco }\end{array}$ & UFPE & Economia solidária \\
\hline $\begin{array}{l}\text { 18/ Incubadoras Universitárias: uma das possibilidades de enfrentamento à extrema pobreza } \\
\text { no Brasil }\end{array}$ & UFSM & Incubadoras \\
\hline 18/ Formação Profissional em Serviço Social: o estado das artes do estágio supervisionado & UNESP & Formação \\
\hline $\begin{array}{l}\text { 18/ Fundo Público, Política Social e Valor: fundamentos históricos, teóricos e dinâmica } \\
\text { contemporânea }\end{array}$ & UERJ & Política Social \\
\hline $\begin{array}{l}\text { 18/ Projeto de educação permanente em saúde para trabalhadores do SUS de Franca/SP e } \\
\text { região }\end{array}$ & UNESP & Saúde \\
\hline $\begin{array}{l}\text { 18/ Estudo avaliativo sobre a implantação da Política de Inclusão para Populações em } \\
\text { Situação de Rua nas capitais do Rio Grande }\end{array}$ & PUCRS & $\begin{array}{l}\text { População em situação } \\
\text { de rua }\end{array}$ \\
\hline 26/ Curso de Especialização em Estudos latino Americanos & UFJF & Formação \\
\hline 32/ Mulheres, Crime, Direitos Reprodutivos & ANIS & Direitos sociais \\
\hline 32/ Mulheres paraibanas: Saúde Sexual e Reprodutiva & UEPB & Saúde \\
\hline 32/ Relações de gênero, trabalho e aposentadoria: um diálogo necessário & PUCRS & Trabalho \\
\hline $\begin{array}{l}\text { 32/ Pesquisa-ação no estudo das condições de vida e de trabalho das catadoras de material } \\
\text { reciclável em Manaus }\end{array}$ & UFAM & Trabalho \\
\hline 32/ Mapeando as mulheres e homens docentes em cursos predominantemente femininos & UFRN & Educação \\
\hline $\begin{array}{l}\text { 32/ Relações sociais de gênero e políticas públicas: uma análise sobre as condições de vida } \\
\text { das mulheres }\end{array}$ & UFPE & Políticas sociais \\
\hline 32/ Organização e trabalho das mulheres ribeirinhas amazônicas & UFAM & Trabalho \\
\hline 32/ Intersexualidade a partir do estudo de trajetórias de vida & UFRGS & Orientação sexual \\
\hline 32/ Relações de gênero e agricultura familiar: estudo na Linha Cerro da Lola Toledo/PR & UNIOESTE & Agricultura familiar \\
\hline
\end{tabular}

Fonte: Elaborado pela autora. 
Em 2013, das 36 pesquisas aprovadas do Serviço Social, 17 eram sobre as políticas sociais com destaque para a assistência social ( 7 pesquisas).

\section{Quadro 4 - Projetos de pesquisa do Serviço Social aprovados em 2013}

\begin{tabular}{|c|c|c|}
\hline N. do edital/ Título do projeto & $\begin{array}{c}\text { IES de } \\
\text { origem/sigla }\end{array}$ & Temática \\
\hline 8/ A implementação da política nacional de educação permanente em saúde & UFF & Saúde \\
\hline $\begin{array}{l}\text { 8/ Onde estão os médicos do Recôncavo da Bahia? Perfil da formação médica, condições e } \\
\text { mercado de trabalho na região }\end{array}$ & UFRB & Trabalho \\
\hline 14/Previdência social e (des) proteção social: uma investigação sobre trabalho e incapacidade & UFRGS & Previdência social \\
\hline 14/ Intersetorialidade, redes e políticas sociais em municípios do oeste catarinense & UNOCHAPECO & Política social \\
\hline $\begin{array}{l}\text { 14/ A gestão do processo de trabalho na saúde pública: a estratégia das organizações sociais e } \\
\text { a empresa pública de direito privado }\end{array}$ & UFES & Trabalho \\
\hline $\begin{array}{l}\text { 14/ Embelezamento de cidades: análise do processo de indenização e reassentamento de } \\
\text { famílias na intervenção do Promaben }\end{array}$ & UFPA & Questão urbana \\
\hline $\begin{array}{l}\text { 14/ Exercício profissional do assistente social: particularidade e conhecimentos mobilizados } \\
\text { para sua efetivação }\end{array}$ & UEL & $\begin{array}{l}\text { Trabalho do assistente } \\
\text { social }\end{array}$ \\
\hline $\begin{array}{l}\text { 14/ A Força Eleitoral dos Clãs Políticos Familiares no Ceará: estudo das décadas de } 1970 \text { a } \\
2010\end{array}$ & UECE & Direitos Políticos \\
\hline 14/ O quilombo de mesquita e os impactos da urbanização & UCB & Questão urbana \\
\hline $\begin{array}{l}\text { 14/ A contrarreforma na política de saúde e o serviço social: expressões e tendências em } \\
\text { Pernambuco }\end{array}$ & UFPE & Saúde \\
\hline 14/ Formação profissional em serviço social na região metropolitana de Belém - Pará & UFPA & Formação \\
\hline $\begin{array}{l}\text { 14/ Política de Assistência Social e a intervenção em rede: análise da rede socioassistencial no } \\
\text { município de Teresina-PI }\end{array}$ & UFPI & Assistência social \\
\hline 14/Fatores de Vulnerabilidade após a cirurgia de Obesidade pelo SUS & PUCRS & Saúde \\
\hline 14/ Serviço social e sistema único de assistência social em Juiz de Fora & UFJF & Assistência social \\
\hline 14/ Política de Assistência Social, centralidade da família e relações de gênero em Teresina & UFPI & Assistência social \\
\hline $\begin{array}{l}\text { 14/ Políticas intersetoriais de Prevenção à Violência Urbana junto às populações em situação } \\
\text { de rua }\end{array}$ & UFRJ & Violência \\
\hline 14/ Mulher, trabalho e assimetria de poder: o assédio moral e sexual no espaço produtivo & UERN & Trabalho \\
\hline $\begin{array}{l}\text { 14/ Políticas de enfrentamento à drogadição no Rio Grande do Sul e a rede de atendimento aos } \\
\text { dependentes químicos e familiares }\end{array}$ & PUCRS & Saúde \\
\hline 14/ Cidadania e representações sociais da velhice: A Matinê da Maturidade & $\mathrm{UCB}$ & Representações sociais \\
\hline 24/ Acesso das famílias de mulheres presas ao Programa Bolsa Família no Distrito Federal & ANIS & Assistência Social \\
\hline $\begin{array}{l}\text { 24/Avaliação do processo de implementação dos Centros-dia de Referência para a Pessoa com } \\
\text { Deficiência e suas Famílias }\end{array}$ & UFRB & Assistência Social \\
\hline $\begin{array}{l}\text { 24/ Os egressos da bolsa família no Maranhão: dimensionamento e impacto sobre suas famílias } \\
\text { e suas vidas }\end{array}$ & UFMA & Assistência Social \\
\hline $\begin{array}{l}\text { 24/ Territórios e vivências: pela efetivação de uma Política de Assistência Social de qualidade } \\
\text { em Barretos (SP) }\end{array}$ & UNIFEB & Assistência Social \\
\hline $\begin{array}{l}\text { 24/ Alimentação enquanto Direito Humano e sua relação com o Programa Camponês no } \\
\text { Estado do Rio Grande do Sul }\end{array}$ & UCPEL & Direitos sociais \\
\hline $\begin{array}{l}\text { 24/ A proteção socioassistencial para usuários de crack e suas famílias: os desafios da } \\
\text { intersetorialidade }\end{array}$ & CEFET/CE & Política social \\
\hline $\begin{array}{l}\text { 43/ HIV/AIDS e desafios para BRICS. Política de Saúde e Direitos no Brasil, África do Sul e } \\
\text { Moçambique }\end{array}$ & UFPE & Saúde \\
\hline 43/ Condições de Acesso das Pessoas com Deficiência às Universidades do RS & PUCRS & Educação \\
\hline 43/ O Trabalho do Assistente Social em Salvador: contribuições para o debate atual & UFBA & $\begin{array}{l}\text { Trabalho do assistente } \\
\text { social }\end{array}$ \\
\hline $\begin{array}{l}\text { 43/ Promoção da Saúde: uma análise das concepções e práticas das equipes dos Núcleos de } \\
\text { Apoio à Saúde da Família (NASF) }\end{array}$ & UEPB & Saúde \\
\hline 43/ Inclusão sócio produtiva de trabalhadores associados & UFPA & Trabalho \\
\hline $\begin{array}{l}\text { 43/ A (des)regulamentação do trabalho do assistente social: um estudo das tendências do } \\
\text { mercado de trabalho }\end{array}$ & UEPB & $\begin{array}{l}\text { Trabalho do assistente } \\
\text { social }\end{array}$ \\
\hline
\end{tabular}




\begin{tabular}{l|l|l|}
$\begin{array}{l}\text { 43/A ação política na periferia: construção de alternativas } \\
\text { 43/ Direitos da Pessoa Idosa: entre o instituído e o vivido no cotidiano dos idosos de } \\
\text { Teresina-PI }\end{array}$ & UFPE & Direitos políticos \\
\hline $\begin{array}{l}\text { 43/ Política de trabalho, emprego e renda no contexto desenvolvimentista: a experiência do } \\
\text { estado do Pará }\end{array}$ & UFPA & Direitos sociais \\
\hline $\begin{array}{l}\text { 89/Incubadora de Empreendimentos Solidários e Tecnologia Social } \\
\text { 89/ Implementação da Incubadora Social }\end{array}$ & PUCRS & Incubadora \\
\hline
\end{tabular}

Fonte: Elaborado pela autora.

As 27 pesquisas financiadas pelo CNPq por meio dos editais de 2014 podem ser assim distribuídas: 13 sobre as políticas sociais; 2 agricultura e questão urbana; 2 formação profissional; 2 trabalho; 2 juventudes; 1 família; 1 movimentos sociais; 1 orientação sexual; 1 pobreza; 1 violência; 1 Estado brasileiro (Quadro 5).

\section{Quadro 5 - Projetos de pesquisa do Serviço Social aprovados em 2014}

\begin{tabular}{|c|c|c|}
\hline N. edital/ Título do projeto & $\begin{array}{c}\text { IES de } \\
\text { origem/sigla }\end{array}$ & Temática \\
\hline 11/ Sertão produtivo: fortalecendo o semiárido & IFBAIANO & Trabalho \\
\hline $\begin{array}{l}\text { 14/ Novas configurações e práticas sociais das famílias usuárias do programa bolsa família } \\
\text { em Belém do Pará }\end{array}$ & UFPA & Assistência Social \\
\hline $\begin{array}{l}\text { 14/ O neodesenvolvimentismo brasileiro e o programa de reformas de combate à pobreza } \\
\text { na era Lula }\end{array}$ & UFPB & Pobreza \\
\hline $\begin{array}{l}\text { 14/ Contrarreforma, intelectuais e serviço social: as inflexões da política de saúde em } \\
\text { Campina Grande/PB }\end{array}$ & UEPB & Saúde \\
\hline $\begin{array}{l}\text { 14/ Processos de coordenação e organização da rede de saúde mental e da assistência social } \\
\text { na atenção em saúde mental }\end{array}$ & UFRGS & $\begin{array}{l}\text { Saúde/Assistência so- } \\
\text { cial }\end{array}$ \\
\hline 14/ Formação profissional do assistente social no estado do Amazonas & UFAM & Formação \\
\hline $\begin{array}{l}\text { 14/ Contribuições da assistência estudantil para a afiliação de alunos na Educação Supe- } \\
\text { rior em contextos de interiorização e internacionalização }\end{array}$ & UFRB & Educação \\
\hline $\begin{array}{l}\text { 14/ Reconfiguração Urbana e Redefinição de Usos do Solo: experiências de intervenções } \\
\text { urbanísticas em Belém. }\end{array}$ & UFPA & Questão urbana \\
\hline 14/ A experiência social das juventudes envolvidas em crimes de roubo & PUCRS & Juventude \\
\hline $\begin{array}{l}\text { 14/ Estudo sobre a sustentabilidade das tecnologias sociais no desenvolvimento do traba- } \\
\text { lho da agricultura familiar }\end{array}$ & UFAM & Agricultura familiar \\
\hline $\begin{array}{l}\text { 14/ Desenvolvimento e Conflitos Sociais nos anos 2000: crítica à razão } \\
\text { neodesenvolvimentista }\end{array}$ & UERJ & Violência \\
\hline 14/ Políticas Públicas para os Jovens: Da Visibilidade à Garantia de Direitos & UEL & Juventude \\
\hline $\begin{array}{l}\text { 14/ Formação em serviço social no século XXI: Configurações, tendências e desafios no } \\
\text { contexto da educação superior }\end{array}$ & PUCRS & Formação \\
\hline $\begin{array}{l}\text { 14/ O Sistema Único de Assistência Social e a perspectiva de gênero: construindo uma } \\
\text { nova história? }\end{array}$ & UNITAU & Assistência social \\
\hline 14/ A Condição Contemporânea do Estado Social no Brasil & UnB & Estado brasileiro \\
\hline 14/ Saúde, serviço social, movimentos sociais e conselhos de saúde & UERJ & Saúde \\
\hline 14/Estudo avaliativo da implementação do Sistema Único de Assistência Social no Brasil & PUC & Assistência social \\
\hline $\begin{array}{l}\text { 14/ Na rota do capital: moradia e trabalho em área portuária da Região Metropolitana da } \\
\text { Baixada Santista }\end{array}$ & UNIFESP & Habitação \\
\hline $\begin{array}{l}\text { 22/ Redes de atendimento, profissionais e pessoas trans no estado do Rio de Janeiro: } \\
\text { conhecendo limites, possibilidades }\end{array}$ & UERJ & Orientação sexual \\
\hline $\begin{array}{l}\text { 22/ Os efeitos do Reuni na gestão das universidades federais: avaliação do desempenho } \\
\text { das instituições beneficiadas }\end{array}$ & UFPI & Educação \\
\hline $\begin{array}{l}\text { 22/ A direção da Pós-Graduação em Serviço Social no Brasil e a importância dos Grupos } \\
\text { e Núcleos de pesquisa na constituição }\end{array}$ & PUCRS & Educação \\
\hline
\end{tabular}




\begin{tabular}{l|c|l|}
\hline $\begin{array}{l}\text { 22/ Investigação sobre o Acesso e Acessibilidade na Atenção Básica da Gestante que se } \\
\text { autodeclara negra ou parda e seu parceiro }\end{array}$ & PUCRS & Saúde \\
\hline 22/ Famílias e Proteção Social na cidade de Niterói & UFF & Famílias \\
\hline $\begin{array}{l}\text { 22/ A condição profissional do Serviço Social no Brasil na atualidade e as particularidades } \\
\text { da realidade alagoana }\end{array}$ & UFAL & $\begin{array}{l}\text { Trabalho do assistente } \\
\text { social }\end{array}$ \\
\hline $\begin{array}{l}\text { 22/ O feminismo como um coletivo total: um estudo sobre os coletivos feministas autô- } \\
\text { nomos no Brasil contemporâneo }\end{array}$ & UERN & Movimentos sociais \\
\hline $\begin{array}{l}\text { 22/ Pactos, protocolos e o protagonismo dos atores políticos locais: impasses e } \\
\text { condicionantes para o acesso aos bens e serviços de saúde na linha de fronteira Arco Sul }\end{array}$ & UCPEL & Saúde \\
\hline $\begin{array}{l}\text { 22/ Elementos intervenientes na proteção social de transfronteiriços indocumentados na } \\
\text { fronteira Arco Sul }\end{array}$ & UCPEL & Política social \\
\hline
\end{tabular}

Fonte: Elaborado pela autora.

Levando em consideração os quatro anos estudados, podemos afirmar que das 118 pesquisas financiadas pelo CNPq do Serviço Social, 52 (44,7\%) estavam relacionadas ao estudo das políticas sociais, com destaque para a seguridade social (35 pesquisas) e mais especificamente a política de saúde (19 pesquisas). Destacam-se também, propostas de estudo sobre o trabalho e o trabalho do assistente social com $21(17,8 \%)$ propostas aprovadas. A temática agricultura, questão urbana e meio ambiente estiveram presentes em 9 $(7,6 \%)$ projetos de pesquisa. Sete $(5,9 \%)$ propostas envolviam a formação profissional e $6(5,1 \%)$ versavam sobre as diversas formas de violências. A seguir citaremos os assuntos que alcançaram a aprovação de 3 projetos cada: direitos sociais; representações sociais; incubadoras. Temas com a aprovação de 2 propostas cada: direitos políticos; orientação sexual; pobreza; juventude. Os demais 6 projetos tiveram como assunto abordado: economia solidária; famílias; população em situação de rua; Estado brasileiro; movimentos sociais; participação e controle social.

Tomando como referência a Avaliação Trienal dos Programas de Pós-Graduação da CAPES/MEC (2001-2003) realizada em 2004, a área de Serviço Social contava com 55 linhas de pesquisa ativas e englobava 581 projetos de pesquisa concluídos ou em andamento. Os eixos políticas sociais, Estado e sociedade civil congregavam 19 linhas de pesquisa $(34,5 \%)$ e 238 projetos $(41 \%)$; relações e processos de trabalho, políticas públicas e Serviço Social contavam com 8 linhas de pesquisa (14,5\%) e 103 projetos (17,7\%); cultura e identidades, processos e práticas sociais incluíam 8 linhas de pesquisa (14,5\%) e 83 projetos (14,3\%); família, relações de gênero e geração, sociabilidade, violência e cidadania articulavam 6 linhas de pesquisa $(10,9 \%)$ e 75 projetos (12,9\%); formação profissional em Serviço Social, fundamentos e exercício da profissão congregavam 7 linhas de pesquisa (12,7\%) e 47 projetos (8\%); movimentos sociais, processos organizativos e mobilização popular com recortes nas relações de poder, conflitos sociais e poder local, questão urbana e rural congregavam 7 linhas de pesquisa $(12,7 \%)$ e 34 projetos $(5,8 \%)$ (IAMAMOTO, 2008).

Sendo assim, os dados encontrados sobre as propostas de pesquisa do Serviço Social aceitas pelo CNPq entre 2011 e 2014, seguem a tendência de concentração das pesquisas do Serviço Social em torno do tema das políticas sociais. Segundo Iamamoto $(2008$, p. 459$)$ a abordagem em torno das políticas sociais ocorre porque é neste campo que se inscreve majoritariamente a atuação do assistente social "em resposta às expressões das desigualdades sociais, condensadas nas múltiplas expressões da questão social". Há ainda que se mencionar o destaque dado aos estudos sobre a seguridade social com maior ênfase na política de saúde. Todavia, existe uma preocupação quanto às pesquisas que incorporam a fragmentação produzida pelas políticas sociais no atendimento às necessidades dos sujeitos sociais e que deixam invisível as relações de classe. A "armadilha está em focalizar os segmentos em si mesmos, fragmentando-os e isolando o seu tratamento analítico das relações sociais que os constituem" (IAMAMOTO, 2008, p. 459). A relevância dada aos estudos sobre trabalho e trabalho profissional também foi identificada na Avaliação Trienal realizada pela CAPES (2001-2003) assemelhando-se ao estudo aqui apresentado.

Dados os limites do texto, consideramos a necessidade de incluirmos, ainda, duas questões para o debate. A primeira, diz respeito ao menor número de projetos com a temática que envolve os movimentos sociais. Dado o compromisso ético-político profissional com a ampliação dos direitos e a transformação societária, entendemos ser importante a realização de estudos que envolvem os movimentos sociais em decorrência do potencial organizativo que estes possuem. Este resultado também foi encontrado em outras pesquisas como os dados da Avaliação Trienal realizada pela CAPES (2001-2003). No caso da pesquisa aqui descrita com os dados do CNPq, nos surpreende que em 2014 fosse aprovada apenas uma pesquisa 
que trata desta temática ${ }^{20}$, dados os acontecimentos vivenciados no país a partir de 2013 com as "jornadas de junho" ${ }^{21}$. O segundo aspecto importante é a inclusão de uma nova temática na agenda de pesquisas do Serviço Social que são os estudos sobre as incubadoras. Dos 118 projetos de pesquisa do Serviço Social aprovados pelo CNPq entre 2011 e 2014, 64 (54,2\%) foram de pesquisadores inseridos em instituições de ensino superior (IES) federais. As instituições e o número de projetos aprovados foram respectivamente: Universidade Federal da Bahia - UFBA (1); Universidade Federal de Santa Catarina - UFSC (1); Universidade Federal de Santa Maria - UFSM (1); Universidade Federal de São Carlos - UFSCAR (1); Universidade Federal de São Paulo - UNIFESP (1); Universidade Federal de Sergipe - UFS (1); Universidade Federal do Rio Grande do Norte - UFRN (1); Universidade Federal do Espírito Santo - UFES (2); Universidade Federal do Rio de Janeiro - UFRJ (2); Universidade Federal Fluminense - UFF (2); Universidade Federal de Juiz de Fora - UFJF (2); Universidade Federal de Alagoas - UFAL (2); Universidade Federal da Paraíba UFPB (2); Universidade Federal do Maranhão - UFMA (3); Universidade Federal do Recôncavo da Bahia - UFRB (4); Universidade Federal do Amazonas - UFAM (5); Universidade de Brasília - UnB (5); Universidade Federal do Rio Grande do Sul - UFRGS (6); Universidade Federal do Piauí - UFPI (6); Universidade Federal de Pernambuco - UFPE (8); Universidade Federal do Pará - UFPA (8). Outras 29 (24,6\%) pesquisas eram provenientes de pesquisadores incluídos em instituições privadas com ou sem fins lucrativos, sendo as instituições e o número de pesquisas aprovadas o seguinte: Centro Universitário da Fundação Educacional - UNIFEB (1); Universidade Católica de Salvador - UCSAL (1); Universidade Comunitária da Região de Chapecó - UNOCHAPECÓ (1); Escola Superior de Ciências da Santa Casa - EMESACAM (1); Instituto de Bioética - ANIS (2); Universidade de Taubaté - UNITAU (2); Pontifícia Universidade Católica de São Paulo - PUC/SP (2); Pontifícia Universidade Católica do Paraná - PUC/PR (2); Universidade Católica de Pelotas - UCPEL (3); Universidade Católica de Brasília - UCB (3); Pontifícia Universidade Católica do Rio Grande do Sul - PUCRS (11). Vinte e três (19,5\%) propostas de pesquisa aceitas eram de IES estaduais citadas a seguir: Universidade Estadual do Ceará - UECE (2); Universidade do Estado do Rio Grande do Norte - UERN (2); Universidade Estadual do Oeste do Paraná - UNIOESTE (2); Universidade Estadual Paulista - UNESP (3); Universidade Estadual de Londrina - UEL (3); Universidade do Estado do Rio de Janeiro - UERJ (5); Universidade Estadual da Paraíba - UEPB (6). É preciso destacar que também houve o financiamento de pesquisas do Serviço Social em instituições de ensino técnico (Institutos Federais) sendo o IFBAIANO (1 pesquisa aprovada) e o CEFET/CE (1 pesquisa aprovada) os representantes.

A partir desses dados, podemos afirmar que as pesquisas do Serviço Social desenvolvidas com o financiamento do CNPq, através dos editais de apoio a pesquisa dos anos de 2011 e 2014, foram desenvolvidas majoritariamente por pesquisadores das instituições de ensino superior federais. Mas há de se destacar que também houve o financiamento com recursos públicos (do CNPq) às instituições privadas com ou sem fins lucrativos, o que nos chama a atenção para esta forma de apropriação dos recursos públicos por instituições privadas. Por fim, destacamos que a maior parte das pesquisas aceitas pelo CNPq no período estudado era proveniente da região nordeste (41 pesquisas ou 34,8\%). Trinta $(25,4 \%)$ eram do sul, $24(20,3 \%)$ eram do sudeste, $13(11 \%)$ eram do norte e $10(8,5 \%)$ eram do centro oeste.

\section{Considerações finais}

A pesquisa realizada mostra uma tendência no Serviço Social quanto à obtenção de financiamento para a produção de conhecimentos ligados principalmente ao estudo das políticas sociais. Neste sentido, embora reconhecendo a importância desta temática para a atuação profissional, destacamos a necessidade de não reproduzirmos uma "relação mimética entre políticas sociais e Serviço Social” (IAMAMOTO, 2008, p. 460), pois esta relação obscurece as particularidades de uma profissão cuja atuação extrapola os limites desta forma de intervenção estatal. Dos 118 projetos aprovados do Serviço Social, 75,4\% foram submetidos por pesquisadores de instituições públicas de ensino. Algumas instituições de ensino privadas também alcançaram a aprovação de projetos obtendo o financiamento público para as suas pesquisas. O financiamento de atividades das instituições privadas com recursos públicos nos remete à problemática das parcerias entre o público e o privado e consequentemente, a captação de recursos do fundo público por estas instituições (RIBEIRO, 2015; $2016 b$ ). Das 355 propostas de pesquisas enviadas ao CNPq pelos pesquisadores da área, apenas 118 (33,2\%) foram aprovadas. Temos uma hipótese (que será estudada em pesquisas futuras) de que o principal motivo para a recusa da maioria dos projetos enviados seja a insuficiência de recursos, uma vez que esta alegação aparece descrita em alguns relatórios institucionais do CNPq (RIBEIRO, 2016a).

Em relação aos editais de pesquisa, também nos chama a atenção à indução dos temas de estudo. Os editais induzem os temas a serem pesquisados e, no caso do Serviço Social, não são todos os editais que 
possibilitam o financiamento de temáticas estudadas por pesquisadores da área. Como demonstramos, dos 135 editais lançados, 55 (40,7\%) não eram voltados a temas das ciências sociais aplicadas.

Um dado interessante é que os pesquisadores do Serviço Social vinculados às instituições da região nordeste alcançaram o maior número de aprovação de propostas de pesquisa. $\mathrm{O}$ estímulo ao desenvolvimento dos programas de pós-graduação bem como da produção de conhecimentos nesta região é uma preocupação presente no IV PNPG ao destacar a necessidade de superação das assimetrias regionais. Os dados descritos colocam algumas questões importantes para a avaliação dos programas de pós-graduação da área e para a formação profissional. Caso ocorra uma diminuição dos recursos públicos para a realização de pesquisas, aliada ao beneficiamento das áreas consideradas mais vantajosas para o capital, enfrentaremos desafios ainda maiores para a manutenção e expansão dos programas de pós-graduação, na medida em que as pesquisas científicas e a sua publicação são os elementos de maior peso na avaliação da CAPES. Diante desta conjuntura, esperamos que o amadurecimento do Serviço Social, no âmbito científico, possibilite a construção de estratégias efetivas frente à disputa dos recursos públicos e à transformação da educação e da ciência em mercadorias.

\section{Referências}

BAPTISTA, M. V.; RODRIGUES, M. L. A formação pós-graduada stricto sensu em Serviço Social: papel da pós-graduação na formação profissional e desenvolvimento do Serviço Social. Cadernos ABESS, São Paulo, n. 5, p. 108-136, 1992.

BRASIL. Coordenação de Aperfeiçoamento de Pessoal de Nível Superior. Plano Nacional de Pós-Graduação (PNPG) 2011 -2020. Vol.1. Brasília, 2010.

Conselho Nacional de Desenvolvimento Científico e Tecnológico - CNPq. Investimentos do CNPq em CT \&I. Brasília, 2015a. Conselho Nacional de Desenvolvimento Científico e Tecnológico - CNPq. Tabela de Áreas do Conhecimento. Brasília, 2015b.

Disponível em: <http://www.cnpq.br/documents/10157/186158/TabeladeAreasdoConhecimento.pdf> Acesso em: 28 de set. de 2015. Coordenação de Aperfeiçoamento de Pessoal de Nível Superior. Dados Quantitativos de Programas Recomendados e Reconhecidos. 2016. Brasília.

BUENO, A. P. A Universidade e os projetos para o país. Revista Caros Amigos, São Paulo, ano 18, n. 70, p. 23-24, 2014.

CURY, C. R. J. Quadragésimo Ano do Parecer CFE n. 977/65. Revista Brasileira de Educação, Rio de Janeiro, n. 30, p. 07-20, 2005.

FAVERO, M. L. A. A Universidade Federal do Rio de Janeiro: origens e construção (1920 a 1965). In: OLIVEIRA, A. J. B. (Org.). A Universidade e os múltiplos olhares de si mesma. v. 1. Rio de Janeiro: UFRJ/FCC/SIBI, 2007. p. 13-42.

IAMAMOTO, M. V. Serviço Social em tempo de capital fetiche: capital financeiro, trabalho e questão social. SP: Cortez, 2008.

LIVRO AZUL DA $4^{a}$ CONFERÊNCIA NACIONAL DE CIÊNCIA E TECNOLOGIA E INOVAÇÃO PARA O DESENVOLVIMENTO SUSTENTÁVEL. Brasília: Ministério da Ciência e Tecnologia/Centro de Gestão e Estudos Estratégicos, 2010.

MACHADO, A. M. N.; ALVES, V. Caminhos ou (des) caminhos da pós-graduação stricto sensu em educação no Brasil. In: REUNIÃO ANUAL DA ASSOCIAÇÃO NACIONAL DE PÓS-GRADUAÇÃO E PESQUISA EM EDUCAÇÃO, 28., 2005, Caxambu. Anais... Caxambu: ANPED, 2005.

MINAYO, M. C. S.; GOMES, S. F. D. R. Pesquisa Social: teoria, método e criatividade. Rio de Janeiro: Vozes, 2011.

RIBEIRO, D. B. A Crise do Capital e seus Rebatimentos para a Produção de Conhecimentos. Textos \& Contextos, Porto Alegre, v.14, n. 2, p. 314-326, 2015.

. As universidades brasileiras e a indução estratégica da pesquisa: o comprometimento da autonomia científica. 2016. Tese (Doutorado em Política Social) - Universidade Federal do Espírito Santo, Espírito Santo, 2016a.

. Pós-graduação, formação e trabalho profissional. Revista Temporalis, Brasília, ano 16, n. 32, p. 73-95, 2016 b.

VERDÚ, C. P.; FERRAZ, A. T. R. La protesta en España y Brasil: crisis económica y crisis política. Revista de Ciencias Sociales, v. 10, n. 2, p. 369-395, 2015.

YASBECK, M. C.; SILVA, M. O. S. Das origens à atualidade da profissão: a construção da pós-graduação em Serviço Social no Brasil. In: CARVALHO, D. B. B.; SILVA, M. O. S. (Orgs.). Serviço Social, pós-graduação e produção de conhecimento no Brasil. São Paulo: Cortez, 2005. p. 25-50.

\section{Notas}

1 Criado em 1808 (MACHADO; ALVES, 2005).

2 Criado em 1827 (MACHADO; ALVES, 2005).

3 Atual Instituto Adolfo Lutz surgido em 1893 (MACHADO; ALVES, 2005).

4 Criado em 1900, atual fundação Oswaldo Cruz e Fiocruz (MACHADO; ALVES, 2005). 
5 A Universidade do Rio de Janeiro (URJ) de 1920 foi a primeira universidade criada que obteve êxito. Em 1937 ela foi designada Universidade do Brasil (UB) e em 1965 recebeu o nome de Universidade Federal do Rio de Janeiro (UFRJ) (FÁVERO, 2007).

6 Criado em 1951. Atualmente Conselho Nacional de Desenvolvimento Científico e Tecnológico (CNPq).

7 Criado em 1951. Atualmente Fundação Coordenação de Aperfeiçoamento de Pessoal de Nível Superior (CAPES).

8 O decreto $^{\circ} 19.851$ de 1931 (conhecido como Estatuto das universidades brasileiras) foi à primeira iniciativa oficial que previa a existência de cursos de aperfeiçoamento e de especialização bem como a necessidade da investigação científica (CURY, 2005).

9 O CNPq reconhece oito grandes áreas do conhecimento (exatas e da terra; biológicas; engenharias; saúde; agrárias; sociais aplicadas; humanas; linguística, letras e artes) e um item denominado outros. As ciências exatas e da terra envolvem: matemática; probabilidade e estatística; ciência da computação; astronomia; física; química; geociências; oceanografia. As ciências biológicas englobam: biologia geral; genética; botânica; zoologia; ecologia; morfologia; fisiologia; bioquímica; biofísica; farmacologia; imunologia; microbiologia; parasitologia. As engenharias são compostas por: engenharia civil; engenharia de minas; engenharia de materiais e metalúrgica; engenharia elétrica; engenharia mecânica; engenharia sanitária; engenharia de produção; engenharia nuclear; engenharia de transportes; engenharia naval e oceânica; engenharia aeroespacial; engenharia biomédica. As ciências da saúde envolvem: medicina; odontologia; farmácia; enfermagem; nutrição; saúde coletiva; fonoaudiologia; fisioterapia e terapia ocupacional; educação física. Fazem parte das ciências agrárias: agronomia; recursos florestais e engenharia florestal; engenharia agrícola; zootecnia; medicina veterinária; recursos pesqueiros e engenharia de pesca; ciência e tecnologia de alimentos. As ciências sociais aplicadas são compostas pelo (a): direito; administração; economia; arquitetura e urbanismo; planejamento urbano e regional; demografia; ciência da informação; museologia; comunicação; serviço social; economia doméstica; desenho industrial; turismo. São consideradas ciências humanas: filosofia; sociologia; antropologia; arqueologia; história; geografia; psicologia; educação; ciência política; teologia. Na área de linguística, letras e artes estão: linguística, letras e artes. São considerados outros (administração hospitalar, administração rural, carreira militar, carreira religiosa, ciências, biomedicina, ciências atuariais, ciências sociais, decoração, desenho de moda, desenho de projetos, diplomacia, engenharia de agrimensura, engenharia cartográfica, engenharia de armamentos, engenharia mecatrônica, engenharia têxtil, estudos sociais, história natural, química industrial, relações internacionais, relações públicas, secretariado executivo) (BRASIL, 2015b).

10 Dados de 2016.

11 Trinta e três do Serviço Social e um da Economia Doméstica que pertence à área do Serviço Social.

12 Cinquenta e um do Serviço Social e um da Economia Doméstica.

13 Trinta e três do Serviço Social e um da Economia Doméstica.

14 Neste trabalho abordaremos apenas as pesquisas do Serviço Social, não englobando as pesquisas da Economia Doméstica que também fazem parte da área.

15 No ano de 2011 foram divulgados 17 editais de apoio à pesquisa, sendo enviados 18.782 projetos e aprovados 4.859 . Em 2012 havia 31 editais para os quais foram submetidos 17.437 projetos e aceitos 5.275. Em 2013 foram lançados 59 editais com o envio de 33.703 projetos e aprovados para fins de financiamento 7.220. Quanto ao ano de 2014, houve a divulgação de 28 editais e a submissão de 23.445 propostas das quais foram aprovadas 7.096 (RIBEIRO, 2016a).

16 Editais do ano de 2011 de números: $05 ; 12 ; 13 ; 17 ; 20 ; 21 ; 22$. Editais referentes ao ano de 2012 de números: $04 ; 15 ; 23 ; 25 ; 30 ; 35 ; 36 ; 39 ; 41 ; 45$; 52. Editais números $09 ; 13 ; 15 ; 19 ; 27 ; 28 ; 29 ; 31 ; 36 ; 38 ; 47 ; 56 ; 62 ; 63 ; 65 ; 67 ; 73 ; 75 ; 76 ; 77 ; 79 ; 86$ do ano de 2013. Editais n ${ }^{\circ} 04 / 2014 ; 05 / 2014$; 18/2014;26/2014; 27/2014;28/2014; 30/2014;32/2014;33/2014;34/2014;35/2014;36/2014;37/2014; 39/2014; 40/2014 (RIBEIRO, $2016 a)$.

17 OVIPNPG coloca como agenda para a pesquisa as seguintes temáticas: "agricultura; Amazônia e o mar; programa espacial; política nuclear; saúde pública; o desafio urbano; educação básica; problemas ligados ao clima, à energia ao pré-sal e as questões sociais pertinentes” (BRASIL, 2010, p. 19). Também explicita quais seriam os desafios brasileiros: água, energia, transporte, controle de fronteiras, agronegócio, Amazônia, mar, saúde, defesa, justiça, segurança pública e criminologia, programa espacial, desequilíbrio regional (BRASIL, 2010).

18 Em 2012, por exemplo, foram aprovados projetos das ciências exatas e da terra através do edital das ciências humanas, sociais e sociais aplicadas. Para maiores detalhes consultar a pesquisa realizada por Ribeiro (2016a).

19 A temática foi escolhida pela pesquisadora mediante o título do projeto. As demais informações foram encaminhadas pelo CNPq.

20 Dos projetos de pesquisa do Serviço Social, enviados e aprovados pelo CNPq em 2014, apenas um trata da temática Movimentos Sociais de forma explícita, intitulado "Saúde, Serviço Social, movimentos sociais e conselhos de saúde".

21 Em junho de 2013 a cidade de São Paulo foi o cenário de manifestações contrárias ao aumento do preço das passagens. Estas manifestações, iniciadas pelo Movimento Passe Livre (MPL), se expandiram e englobaram outras reivindicações frente às insatisfações populares quanto a não efetivação de algumas políticas públicas. Ao conjunto das reivindicações somaram-se movimentos contra a corrupção que se espalharam pelo país, conduzidos por grupos de diferentes orientações políticas (VERDÚ; FERRAZ, 2015).

\section{Daniella Borges Ribeiro}

dborgesribeiro@yahoo.com.br

Doutorado em Política Social pela Universidade Federal do Espírito Santo (UFES)

Professora do Departamento de Ciências Sociais, Comunicação - Jornalismo e Serviço Social da Universidade Federal de Ouro Preto (UFOP) 
UFOP

Rua do Catete, $\mathrm{n}^{\circ} 166$, Centro

Mariana - Minas Gerais - Brasil

CEP: 35.420-000 